\title{
Choke in a Cow - A Case Report
}

\author{
B Vishwanatha, L Ranganath, V Mahesh*, Ramesh Rathod \\ Department of Veterinary Surgery and Radiology, \\ Veterinary College, KVAFS University, Bangalore-24, India. \\ * Corresponding author email: dr.vmahesh@gmail.com \\ Received: 24-08-2011, Accepted: 18-09-2011, Published Online: 17-11-2011 \\ doi: 10.5455/vetworld.2012.40-41
}

\section{I ntroduction}

In cattle, acute and complete oesophageal obstruction is an emergency because it prohibits the eructation of ruminal gases, and free-gas bloat develops. Objects lodged in the cervical oesophagus may be located via palpation. Endoscopic evaluation and the inability to pass a stomach or nasogastric tube in horses or cattle can also confirm the diagnosis. The primary indication for esophageal surgery in large animals is to relieve esophageal obstructions (choke) which have not responded to conservative treatment (Meagher and Mayhew, 1978). The present study reports the cervical choke caused by a mango and its surgical management.

\section{Case History and Observation}

A four year old female cross bred HolsteinFriesian heifer that had swallowed a mango in the night with signs of drooling saliva was referred to

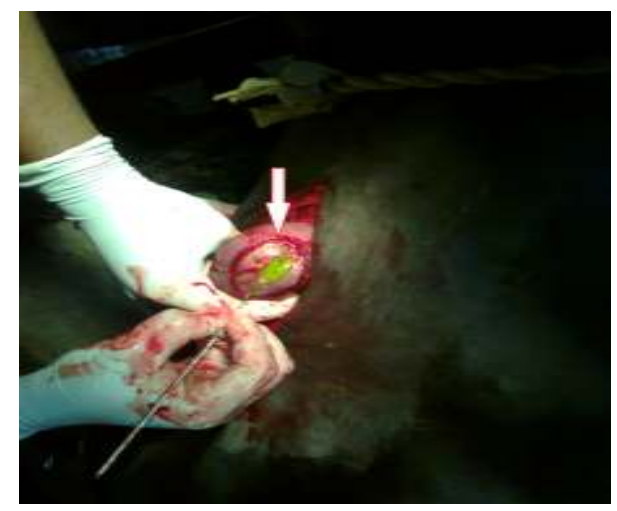

Figure. 1: Incision on the esophagus at the site of obstruction the Dept. of Veterinary Surgery and Radiology, Veterinary College Hospital, Hebbal, Bangalore for treatment. Trocarization has been done to relieve the tympany by a local veterinarian. On clinical examination, swelling was noticed at the mid cervical oesophageal region and palpation revealed a round movable mass at the region. A 2 $\mathrm{cm}$ diameter stomach tube was passed to confirm the seat of obstruction. The rectal temperature, respiratory rate and pulse rate were normal. An attempt was made to remove the foreign body manually, but it failed, hence it was decided to subject the animal for esophagotomy.

Surgical Treatment: Feed was withheld for 48 hours and water for 24 hours prior to surgery. The cow was premedicated with Triflupromazine @ $0.1 \mathrm{mg} / \mathrm{kg}$ body weight intravenously. Surgical site was prepared aseptically and local analgesia was achieved by field block using $2 \%$ Lignociane hydrochloride. A $10 \mathrm{~cm}$ incision was made on the

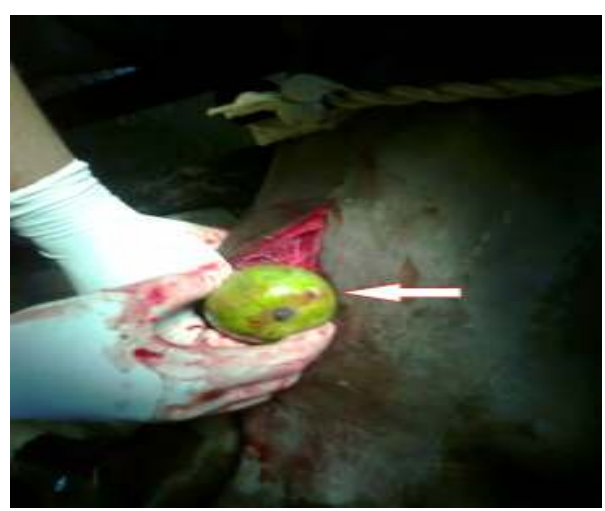

Fig. 2: Removal of foreign body 
left side over the mass and along the dorsal aspect of the jugular furrow. Muscles were separated and the esophagus was exposed. A $5 \mathrm{~cm}$ longitudinal incision was made through the lateral wall of the esophagus (Fig. 1) and the foreign body (raw mango) was removed (Fig. 2). The mucosal layer was sutured with simple interrupted sutures utilizing chromic catgut No. 1-0 as intraluminal sutures. The submucosa and muscularis were closed in one layer using a simple continuous suture pattern with No. 1-0 chromic catgut. The muscles and skin were closed in routine manner. Postoperatively animal was administered Streptopenicillin for five days and maintained on parenteral administration for four days. There were no post operative complications and animal recovered uneventfully.

\section{Discussion}

Hofmeyr (1974) reported that $80 \%$ of oesophageal obstruction occurs in the cervical region in cattle Oesophageal obstruction due to a mango and its surgical management in a heifer was reported by Veena et al. (2000) and stated that the obstruction could be relieved easily if the obstruction is in the cervical region. Sreenu and Sureshkumar (2001) reported successful surgical management of esophageal obstruction by tarpaulin cloth in a buffalo calf. In the present report, choke caused by a mango at the cervical region was managed successfully by surgical approach.
Ruben, (1997) reported the risk of postoperative complications associated with an esophagotomy as incisional dehiscence and fistula formation but in present case, no such complications were seen. Wilmot et al., (1989) reported that administration of a regional local anesthetic works by diminishing oesophageal muscle spasm and thus facilitates external oesophageal massage and removal of the foreign body.

\section{References}

1. Holfmeyr, C. F. B. (1974). Obstruction of oesophagus by tarpaulin cloth in a buffalo calf. Indian Vet. J., 78; 243-244.

2. Meagher, D. M. and Mayhew, I. G. 1978. The surgical treatment of upper esophageal obstruction in the bovine. Can. vet. J., 19; 128-132.

3. Ruben., J. M. (1997). Surgical removal of a foreign body from the bovine oesophagus. Vet Rec. 100:220.

4. Sreenu, M and Sureshkumar, R. V. (2001). Obstruction of oesophagus by tarpaulin cloth in a buffalo calf. Indian Vet. J., 78; 243-244.

5. Veena, P., Ravikumar, A. and Ramakrishna, O. (2000). Oesophageal obstruction by mango in a heifer. Indian Vet. J., 77; 794.

6. Wilmot., L., Saint., J. G., and Hoffsis., G. S. (1989). Surgical treatment of an esophageal laceration in a calf Can Vet J. 30:175-177. 